Coronary heart disease secondary to atherosclerosis is still the leading cause of death in the US. Animal models used for elucidating the pathogenesis of this disease primarily involve rabbits and pigs. Previous studies from this laboratory have demonstrated intraperitoneal injections of poloxamer 407 (P-407) in both male and female mice will lead to hyperlipidemia and atherosclerosis, suggesting the use of this polymer to develop a mouse model of atherosclerosis. In order to understand the mechanism of P-407induced hyperlipidemia and vascular lesion formation, we evaluated the direct effects of $P-407$ on endothelial cell and macrophage functions in vitro, and its in vivo effects on the oxidation of circulating lipids following long-term ( 4 month) administration. Our results demonstrated that incubation of $\mathrm{P}-407$ with human umbilical vein endothelial cells in culture did not influence either cell proliferation or interleukin-6 and interleukin-8 production over a concentration range of $0-40 \mu \mathrm{M}$. In addition, nitric oxide production by macrophages was not affected by $\mathrm{P}-407$ over a concentration range of $0-20 \mu \mathrm{M}$. Finally, we demonstrated that while $P-407$ could not induce the oxidation of LDL-C in vitro, long-term (4 month) administration of $\mathrm{P}-407$ in mice resulted in elevated levels of oxidized lipids in the plasma. Thus, it is suggested that the formation of atherosclerotic lesions in this mouse model of atherosclerosis does not result from either direct stimulation of endothelial cells or macrophage activation by $P-407$. Instead, these data would support the premise that oxidation of lipids (perhaps low-density lipoprotein cholesterol) by an indirect mechanism following injection of $\mathbf{P}-407$ may represent one of the mechanisms responsible for atheroma formation.

Key words: Atherosclerosis, Inflammation, Interleukins, Lipid oxidation, Low-density lipoprotein, Nitric oxide

\section{Poloxamer 407-induced atherosclerosis in mice appears to be due to lipid derangements and not due to its direct effects on endothelial cells and macrophages}

Thomas P. Johnston ${ }^{1, \mathrm{CA}}$, Yuai $\mathrm{Li}^{2}$, Ahmed S. Jamal ${ }^{1}$, Daniel J. Stechschulte ${ }^{2}$ and Kottarappat N. Dileepan ${ }^{2}$

${ }^{1}$ Division of Pharmaceutical Sciences, Room 211A, School of Pharmacy, University of Missouri, 5005 Rockhill Road, Kansas City, MO 64110-2499, USA; and ${ }^{2}$ Division of Allergy, Clinical Immunology, and Rheumatology, Department of Medicine, University of Kansas Medical Center, Kansas City, KS, USA

\author{
${ }^{\mathrm{CA}}$ Corresponding author \\ Tel: + 18162351624 \\ Fax: + 18162355190 \\ E-mail: johnstont@umkc.edu
}

\section{Introduction}

Death due to coronary heart disease caused by atherosclerosis continues to be a leading cause of mortality in affluent nations of the world. The prevalence is maximally apparent in individuals with elevated concentrations of low-density lipoprotein cholesterol (LDL-C) and a genetic predisposition to this multifactorial disease. ${ }^{1,2}$

To assist in the search for answers to the pathogenesis of atherosclerosis, various animal models have been developed. ${ }^{3}$ Atherosclerosis has historically been studied in rabbits ${ }^{4}$ and pigs. ${ }^{5}$ However, in recent years, the mouse has proven to be an important animal model to dissect many factors that contribute to atherosclerotic heart disease. ${ }^{6}$ While each animal model has its own particular limitations and merits, the mouse has emerged as a model with some definite advantages. Mice are rather inexpen- sive and are one of the most well-characterized mammals to date. As such, gene-deficient ('knockout') mice such as low-density lipoprotein receptor, apolipoprotein E, and others have been bred to determine what effect the deletion of a single gene has on the natural progression of atherosclerosis. The validity of classic cholesterol-fed rabbit models would appear questionable since the rabbit is a herbivore. Fat-fed, non-transgenic mouse models (e.g. wild-type C57BL/6 mice) typically contain cholic acid in the diet to induce atheroma formation. ${ }^{7}$ Cholic acid has been cited as a potential proinflammatory agent to vascular endothelium and may, in and of itself, be the causative agent for induction of atherosclerosis in this model. ${ }^{6}$ Thus, it can be seen that no one animal model is ideal for the study of atherosclerotic heart disease, but rather each model has its own advantages and disadvantages.

Recently, a new mouse model to study mechanisms associated with hyperlipidemia and athero- 
sclerosis has been developed in our laboratory. ${ }^{8-17}$ The model involves the administration of a non-ionic surface-active agent (surfactant) called poloxamer 407 (P-407) to either male or female C57BL/6 mice. One $0.5 \mathrm{~g} / \mathrm{kg}$ injection of $\mathrm{P}-407$ results in marked hypercholesterolemia ( $>800 \mathrm{mg} / \mathrm{dl}$ ) and profound hypertriglyceridemia $(>5000 \mathrm{mg} / \mathrm{dl}$ ) for greater than 4 days. ${ }^{8,9,13}$ The precise degree of both hypercholesterolemia and hypertriglyceridemia desired may be obtained by simple titration of the administered dose. ${ }^{8}$ Long-term administration of P-407 (4 months) to either sex of this mouse strain produces aortic atherosclerotic lesions. ${ }^{13}$

The P-407 mouse model of hyperlipidemia and atherosclerosis has several advantages over other current mouse models of atherosclerosis. For example, the P-407 mouse model of atherosclerosis, which utilizes wild-type $\mathrm{C} 57 \mathrm{BL} / 6$ mice, does not require cholic acid in the diet for lesion formation. ${ }^{13}$ In addition, aortic atherosclerotic lesions are formed in a time frame equivalent to well-accepted, fat-fed, nontransgenic models, ${ }^{13,15,16}$ the biological activity of key enzymes involved in lipid metabolism (cholesterol $7 \alpha$-hydroxylase, lipoprotein lipase, and hepatic lipase) are predictably altered, ${ }^{9,17,18}$ the model permits evaluation of the potency of a number of antihyperlipidemic drugs of various classes [nicotinic acid, fibric acid derivatives, and HMG-CoA reductase inhibitor drugs (statins)], ${ }^{18-21}$ and the model allows for the assessment of pharmacological agents that may cause regression of $\mathrm{P}-407$-induced atherosclerotic lesions. ${ }^{15}$

There is overwhelming evidence indicating that atherosclerosis is a multifactorial disease and involves inflammatory responses by endothelial cells and macrophages. The purpose of the present investigation was to determine whether P-407-induced atherosclerosis is strictly associated with lipid derangements or is also mediated by inflammatory responses. These variables were studied to better characterize the P-407 mouse model of atherosclerosis in an attempt to identify key factors involved in atheroma formation in humans. The results presented in the present report would suggest that the progression of atherosclerotic lesion formation in C57BL/6 mice treated with $\mathrm{P}-407$ is predominantly due to increased LDL-C and triglycerides, and may not be due to direct effects of the polymer on endothelial cells or macrophage activation.

\section{Materials and methods}

\section{Materials}

Human umbilical vein endothelial cells (HUVEC) were obtained from Clonetics (San Diego, CA, USA). Minimal essential medium and fetal bovine serum were purchased from Hyclone Laboratories (Logan, UT, USA). Heparin, $N$-2-hydroxyethyl-piperazine- $N^{\prime}$-2-ethanesulfonic acid (HEPES), penicillin, streptomycin, and lipopolysaccharide (LPS) (Escherichia coli), endothelial cell growth supplement, human LDL-C (lot number 88H9275), cupric sulfate, thiobarbituric acid, and ferric chloride were obtained from Sigma Chemical Co. (St Louis, MO, USA). Soybean-derived trypsin inhibitor was purchased from Boehringer Mannheim (Indianapolis, IN, USA). F-12K medium and trypsin-ethylenediamine tetraacetate (EDTA) were obtained from Life Technologies (Grand Island, NY, USA). The enzyme-linked immunosorbent assay (ELISA) kits for interluekin (IL)-6 and IL-8 were purchased from R\&D Systems, Inc. (Minneapolis, MN, USA) and BioSource International (Camarillo, CA, USA), respectively. Sprague-Dawley rats (350-400 g) were obtained from Harlan Sprague-Dawley (Indianapolis, IN, USA) and 5week-old to 6-week-old, female C57BL/6 mice (average weight $=15.2 \pm 1.4 \mathrm{~g}$ ) were obtained from the Jackson Laboratory (Bar Harbor, ME, USA). The lowfat mouse diet (Formulab diet 5008) consisted of 6.5\% fat, $280 \mathrm{ppm}$ cholesterol, linoleic acid (1.4\%), linolenic acid (0.09\%), arachidonic acid (0.01\%), omega-3 fatty acids (0.3\%), total saturated fatty acids (2.5\%), and total monounsaturated fatty acids (2.3\%) and was obtained from PMI Nutrition International, Inc. (Brentwood, MO, USA). The high-fat diet (Diet number TD-88051) consisted of $12 \%$ fat, high-protein casein $(7.5 \%)$, dextrose $(2.5 \%)$, sucrose $(1.6 \%)$, dextrin $(0.6 \%)$, cocoa butter $(7.5 \%)$, cholesterol (1.3\%), sodium cholate $(0.5 \%)$, cellulose $(1.3 \%)$, Teklad mineral and vitamin mix (1.1\%), and choline chloride (0.1\%), and was supplied by Harlan Teklad (Madison, WI, USA).

\section{Collection and isolation of peritoneal macrophages from rats}

Three-month-old to four-month-old male SpragueDawley rats were the source of peritoneal macrophages. The methods employed for the isolation of macrophages have been previously described. ${ }^{22,23}$ Briefly, the peritoneal cavity of each rat was lavaged under sterile conditions with Minimum Essential Medium containing $15 \mathrm{mM}$ HEPES, $100 \mathrm{U} / \mathrm{ml}$ penicillin, $100 \mu \mathrm{g}$ streptomycin, 10\% fetal bovine serum (HMEM), and $5 \mathrm{U} / \mathrm{ml}$ heparin. The peritoneal cells were then pooled, centrifuged at $250 \times g$ for $10 \mathrm{~min}$ at room temperature, and washed twice with HMEM. Two-milliliter aliquots of the cell suspension [(6$8) \times 10^{7}$ cells) were layered on $4 \mathrm{ml}$ columns of $22.5 \%(\mathrm{w} / \mathrm{v}$ ) metrizamide (density $1.125 \mathrm{~g} / \mathrm{ml}$ ) in HMEM, and centrifuged at $200 \times g$ for $15 \mathrm{~min}$. Macrophages were collected at the gradient interface, and mast cells were sedimented at the bottom. The macrophage fractions were collected, pooled, 
washed twice and resuspended in HMEM. Macrophages collected by this procedure exceeded $95 \%$ in purity and viability when tested by trypan blue exclusion.

\section{Culture of HUVEC}

HUVEC were grown in endothelial cell growth medium (EGM-2MV) supplemented with the recommended growth factors (Clonetics) and 5\% fetal bovine serum. ${ }^{24}$ At confluence, the cells were detached from the culture flasks using trypsin-EDTA, washed twice, and re-suspended in complete culture medium. All experiments described employed cells between five to eight passages.

\section{Determination of the production of IL-6 and IL-8 by HUVEC}

The quantification of IL- 6 and IL-8 production by HUVEC was conducted as previously described. ${ }^{25}$ Briefly, HUVEC $\left(2 \times 10^{4}\right)$ were added to each well of a 96-well flat-bottom microtiter plate and allowed to adhere for $24 \mathrm{~h}$ in EGM complete medium. After the cell adherence, P-407 $(0-40 \mu \mathrm{M})$, LPS $(50 \mathrm{ng} / \mathrm{ml})$, P$407+$ LPS, or medium was added to HUVEC monolayers and the final volume adjusted to $0.2 \mathrm{ml}$ with complete EGM. All incubations were carried out at $37^{\circ} \mathrm{C}$ in a $\mathrm{CO}_{2}$ incubator for 24 or $48 \mathrm{~h}$ unless otherwise indicated. After the incubation, aliquots of the culture supernatants were collected, appropriately diluted, and assayed for IL-6 and IL-8 according to the instructions provided by the ELISA kit manufacturers. The cytokine levels were quantified by comparison with a standard curve run concurrently, utilizing recombinant human IL-6 and IL-8.

\section{Endothelial cell proliferation assay}

The direct effect of P-407 on endothelial cell proliferation was determined by quantifying total cellular nucleic acid content using a commercially available assay kit (Molecular Probes, Eugene, OR, USA), according to the manufacturer's instructions. Briefly, HUVEC $\left(2 \times 10^{4}\right)$ were added to each well of a 96well flat-bottom microtiter plate and allowed to adhere for $24 \mathrm{~h}$ in complete EGM. After cell adherence, P-407 $(0-40 \mu \mathrm{M})$, LPS $(50 \mathrm{ng} / \mathrm{ml})$, P$407+$ LPS, or medium was added to HUVEC monolayers and the final volume adjusted to $0.2 \mathrm{ml}$ with complete EGM. After incubation at $37^{\circ} \mathrm{C}$ in a $\mathrm{CO}_{2}$ incubator for 24 or $48 \mathrm{~h}$, the cells were washed twice with Hank's balanced salt solution. Next, $200 \mu \mathrm{l}$ appropriately diluted Cyquant ${ }^{\mathrm{TM}}$ reagent (Molecular Probes) was added to each of the wells and the plates incubated in darkness for $5 \mathrm{~min}$ at room temperature. The intensity of fluorescence was measured at excitation and emission wavelengths of $480 \mathrm{~nm}$ and $520 \mathrm{~nm}$, respectively, using a Model $f$-max microtiter plate fluorescence reader (Molecular Devices Corp., Sunnyvale, CA, USA).

\section{Measurement of nitric oxide production from rat peritoneal macrophages}

Peritoneal macrophages from rats were obtained via peritoneal lavage as already described and descried previously. ${ }^{22}$ Briefly, $0.2 \mathrm{ml}$ aliquots of the cell suspension containing $2 \times 10^{5}$ macrophages were added to each of the wells of a 96-well culture plate and allowed to adhere for $2 \mathrm{~h}$. Next, the nonadherent cells were removed by washing with HMEM. Macrophage monolayers were incubated at $37^{\circ} \mathrm{C}$ for $18 \mathrm{~h}$ with varying concentrations of P-407 (0, $1.25,2.5,5,10$, and $20 \mu \mathrm{M}$ ) both in the presence (50 $\mathrm{ng} / \mathrm{ml}$ ) and absence of LPS [a known inducer of nitric oxide (NO) production]. Synthesis and release of nitric oxide by macrophages were determined by assay of culture supernatants for nitrite content using Griess reagent as previously described. ${ }^{26}$

\section{Lipid oxidation studies}

P-407 was evaluated over a concentration range of $0.001-10,000 \mu \mathrm{M}$ for its capacity to oxidize LDL-C in vitro using the thiobarbituric acid reactive substances (TBARS) assay. ${ }^{27}$ LDL-C alone served as a negative control while LDL-C + cupric sulfate $\left(\mathrm{CuSO}_{4}\right)$ served as a positive control. The absorbance values for aqueous P-407 solutions over the concentration range $0.001-10,000 \mu \mathrm{M}$ was also determined. Finally, the contribution, if any, of $\mathrm{P}-407$ to the absorbance values obtained with $\mathrm{LDL}-\mathrm{C}+\mathrm{CuSO}_{4}$ was determined to assess whether P-407 could either oxidize LDL-C when in the presence of $\mathrm{CuSO}_{4}$ or enhance the capacity of $\mathrm{CuSO}_{4}$ to oxidize LDL-C. It should be noted that the commercially obtained LDL-C solution was first dialyzed to remove EDTA, which would interfere with copper-induced oxidation of LDL-C. All solutions were then analyzed using the TBARS assay according to the method of Schmedes and $\mathrm{H} \mathrm{lmer}^{27}$ described in brief in the following.

Solution A required for the TBARS assay was prepared by dissolving $233 \mathrm{mg}$ thiobarbituric acid in $4 \mathrm{ml}$ doubly deionized water. Next, approximately $36 \mathrm{ml}$ glacial acid was added to bring the total volume to $40 \mathrm{ml}$. Solution B utilized in the TBARS assay was prepared by combining $127 \mathrm{mg}$ sodium sulfite and $2.93 \mathrm{mg} \mathrm{FeCl}$ in a total volume of $2.33 \mathrm{ml}$.

Solution A and Solution B were combined no more than $30 \mathrm{~min}$ prior to conducting the assay. To perform the TBARS assay, dialyzed samples of LDLC ( $214 \mu \mathrm{g} ; 31 \mu \mathrm{l}$ of a $6.9 \mathrm{mg} / \mathrm{ml}$ solution) were added to $10 \mathrm{ml}$ pyrex test tubes with a screw cap. To tubes that evaluated the effect of P-407 on the oxidation of 
LDL-C, $200 \mu \mathrm{l}$ of each P-407 concentration evaluated was added to individual tubes that contained $31 \mu \mathrm{l}$ LDL-C. To the four test tubes that served as the negative control, $200 \mu \mathrm{l}$ water was added to the $31 \mu \mathrm{l}$ LDL-C. The four tubes that served as the positive control contained $200 \mu \mathrm{l}$ of $10 \mathrm{mM} \mathrm{CuSO}_{4}+31 \mu \mathrm{l}$ LDL-C. Finally, tubes that evaluated either the effect of $\mathrm{P}-407$ on the assay procedure or the effect of $\mathrm{P}-407$ when combined with LDL-C $+\mathrm{CuSO}_{4}$ contained either $200 \mu \mathrm{l}$ of each P-407 concentration evaluated plus $31 \mu \mathrm{l}$ water or $100 \mu \mathrm{l}$ of $10 \mathrm{mM} \mathrm{CuSO}_{4}, 100 \mu \mathrm{l}$ of a $2 \times$ concentration of each $\mathrm{P}-407$ solution prepared earlier, and $31 \mu \mathrm{l}$ LDL-C, respectively. To each test tube in these five groups was added an additional 102 $\mu \mathrm{CHCl}_{3}$ to bring the entire volume of an individual test tube to $333 \mu \mathrm{l}$. All tubes were then incubated overnight $(18 \mathrm{~h})$ at $37^{\circ} \mathrm{C}$.

Following the overnight incubation, $533 \mu \mathrm{l}$ of the combined solutions A and B (see earlier) was added to each tube. The tubes were then capped tightly and boiled for $30 \mathrm{~min}$ followed by placement in cool water to obtain room temperature. Next, $333 \mu \mathrm{l}$ of a $10 \%$ trichloroacetic acid was added to each tube and the contents vortexed for $30 \mathrm{sec}$. The contents of each tube were then individually transferred to separate $1.5 \mathrm{ml}$ polypropylene eppendorf tubes, centrifuged at $2000 \mathrm{rpm}$ for $10 \mathrm{~min}$, and then the supernatant transferred into $1.5 \mathrm{ml}$ disposable cuvettes. The absorbance of each solution was then determined at $532 \mathrm{~nm}$ using a Beckman DU $7400 \mathrm{UV} /$ vis spectrophotometer (Fullerton, CA, USA).

\section{Quantification of oxidized lipids in the plasma of mice treated with $\mathrm{P}-407$}

Treatment groups comprised eight mice injected intraperitoneally with normal saline every third day for 4 months, eight mice injected intraperitoneally with P-407 $(0.5 \mathrm{~g} / \mathrm{kg})$ every third day for 4 months, and eight mice fed a high-fat, high-cholesterol diet for 4 months. Blood samples were obtained by periorbital bleeding at the 4-month sacrifice date from each of the three treatment groups, the plasma harvested, and the plasma immediately analyzed for oxidized lipids using the TBARS assay. In the analysis, $167 \mu \mathrm{l}$ plasma collected from each of six mice in each group was combined with an equal volume of $\mathrm{CHCl}_{3}$ and individually assayed as already described. These results were expressed as the mean OD \pm the standard deviation of six mice. Mice in all groups were housed (three animals/cage) under controlled conditions at temperatures between 21 and $23^{\circ} \mathrm{C}$. The animals were provided unrestricted access to water and the appropriate mouse chow described earlier throughout the 4-month study. All procedures for P-407 administration and subsequent blood collection were in accordance with the institution's guide for the care and use of laboratory animals, and the treatment protocol was approved by the Animal Care Committee at the University of Missouri-Kansas City.

\section{Data analysis}

All data presented in this study are expressed as the mean \pm standard deviation of the mean value. Statistical analysis consisted of the Student's $t$-test for comparing two mean values and a one-way analysis of variance (ANOVA) when more than two mean values were compared. If a value of $p<0.05$ associated with an $F$ value was obtained following the ANOVA, a post boc analysis was performed according to the method of Scheffé to identify significantly different mean values. ${ }^{28}$

\section{RESULTS}

\section{Cell proliferation assay}

To evaluate the direct effect of P-407 on endothelial cell proliferation, HUVEC were cultured for 24 and 48 $\mathrm{h}$ with varying concentrations of the polymer, including concentrations that spanned the maximum plasma concentration obtained following a standard $0.5 \mathrm{~g} \mathrm{P}-407 / \mathrm{kg}$ body weight injection to mice. ${ }^{10}$ As evident from the data presented in Table 1, the relative fluorescence units obtained from cells incubated with P-407 were not significantly $(p>0.05)$ different from values obtained from control cells (cells not incubated with $\mathrm{P}-407$ ) regardless of the presence of LPS, indicating that P-407 does not alter endothelial cell proliferation or cell viability. The presence of LPS in the HUVEC culture did not result in a significant increase in cell proliferation either in the absence or presence of P-407 when compared with corresponding values for control HUVEC (no LPS) at both 24 and $48 \mathrm{~h}$ (Table 1).

\section{Production of IL- 6 and IL-8 by HUVEC in vitro}

The direct effect of P-407 on the production of proinflammatory cytokines was assessed by monitoring the release of IL- 6 and IL- 8 from HUVEC treated with $\mathrm{P}-407$. The results demonstrated that $\mathrm{P}-407$, over a concentration range of $0-40 \mu \mathrm{M}$, had no effect on the production of IL-6 by HUVEC (Fig. 1). The average concentration of IL- 6 detected when HUVEC were cultured in the presence of P-407 $(0-40 \mu \mathrm{M})$ was approximately $100 \mathrm{pg} / \mathrm{ml}$ regardless of whether IL-6 concentrations were determined after 24 or $48 \mathrm{~h}$ of incubation. On the other hand, incubation of HUVEC with LPS $(50 \mathrm{ng} / \mathrm{ml})$ stimulated HUVEC to produce IL-6 (400 pg/ml). Incubation of HUVEC monolayers with P-407 in the presence of LPS did not further enhance IL-6 production. The results 
Table 1. Effect of P-407 on proliferation of HUVEC at 24 and $48 \mathrm{~h}$

\begin{tabular}{crrrrr}
\hline \multirow{2}{*}{$\begin{array}{l}\text { Concentration of } \\
\text { P-407 }(\mu \mathrm{M})\end{array}$} & \multicolumn{2}{c}{$24 \mathrm{~h}$} & & \multicolumn{2}{c}{$48 \mathrm{~h}$} \\
\cline { 2 - 3 } \cline { 5 - 6 } \cline { 5 - 6 } & No LPS & LPS $(50 \mathrm{ng} / \mathrm{ml})$ & No LPS & LPS $(50 \mathrm{ng} / \mathrm{ml})$ \\
\hline 0.0 & $10.45 \pm 0.18$ & $9.34 \pm 0.44$ & & $10.97 \pm 1.82$ & $11.79 \pm 1.87$ \\
1.25 & $11.37 \pm 0.93$ & $9.73 \pm 0.94$ & & $9.54 \pm 1.15$ & $9.46 \pm 1.77$ \\
2.5 & $11.66 \pm 1.38$ & $8.68 \pm 0.15$ & & $10.78 \pm 2.27$ & $10.17 \pm 1.63$ \\
5.0 & $12.01 \pm 1.19$ & $10.08 \pm 0.66$ & & $9083 \pm 1.92$ & $9.64 \pm 1.51$ \\
10 & $11.02 \pm 0.69$ & $10.12 \pm 1.07$ & & $9.15 \pm 1.35$ & $9.96 \pm 0.75$ \\
20 & $11.23 \pm 1.02$ & $10.33 \pm 0.63$ & & $10.66 \pm 1.83$ & $10.19 \pm 1.92$ \\
40 & $10.98 \pm 0.76$ & $9.84 \pm 0.72$ & & $11.38 \pm 2.41$ & $12.82 \pm 1.48$ \\
\hline
\end{tabular}

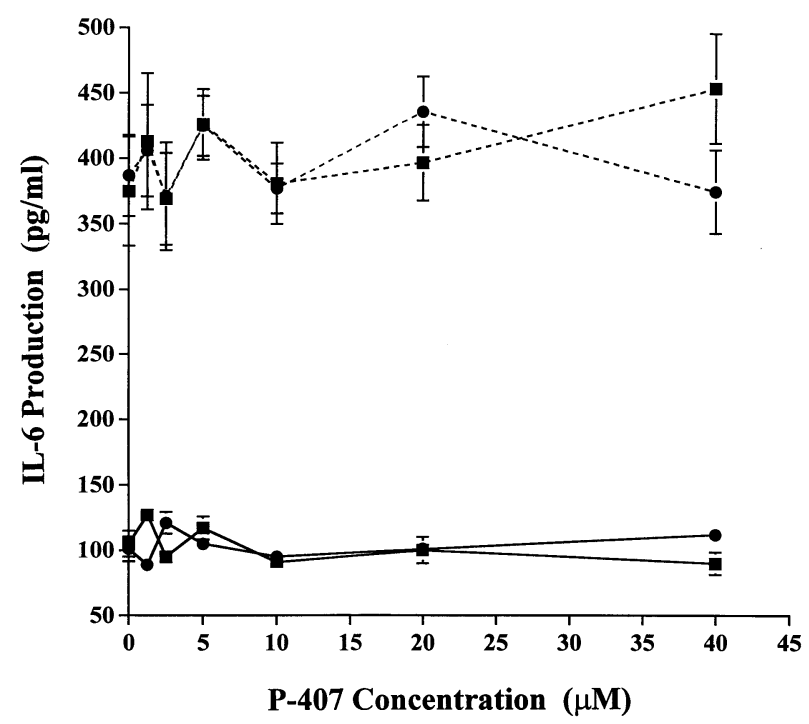

FIG. 1. Effect of P-407 on IL-6 release from HUVEC. Concentration of IL- 6 in the absence of LPS at $24 \mathrm{~h}$ (solid line, $\mathbf{\square})$ and $48 \mathrm{~h}$ (solid line, ), and in the presence of LPS $(50 \mathrm{ng} / \mathrm{ml})$ at $24 \mathrm{~h}$ (dashed line, $\mathbf{0}$ ) and $48 \mathrm{hr}$ (dashed line, 0 ).

show that P-407 neither induces IL-6 production by HUVEC nor modulates the cytokine production that was induced by LPS.

As can be noted in Fig. 2, no significant $(p>0.05)$ difference in IL-8 production was observed between naive and P-407-treated HUVEC after $24 \mathrm{~h}$ in culture. As expected, the addition of $50 \mathrm{ng} / \mathrm{ml}$ LPS to the cell culture induced a significant increase in IL-8 release with mean IL-8 concentrations of approximately 5000 $\mathrm{pg} / \mathrm{ml}$ and $13,000 \mathrm{pg} / \mathrm{ml}$, for the naive and LPStreated cells, respectively (Fig. 2). Again, P-407 was ineffective at activating IL-8 production by naive or LPS-stimulated endothelial cells.

\section{Effect of P-407 on rat peritoneal macrophage NO production}

The production of NO by macrophages plays a significant role in vascular physiology and atherosclerosis. Therefore, in the present study, the effect of P-407 on NO production by rat peritoneal macrophages was evaluated. The basal level of $\mathrm{NO}$ production by unactivated macrophages was $2.50 \pm$ $0.41 \mu \mathrm{M}$ and was not significantly affected by the

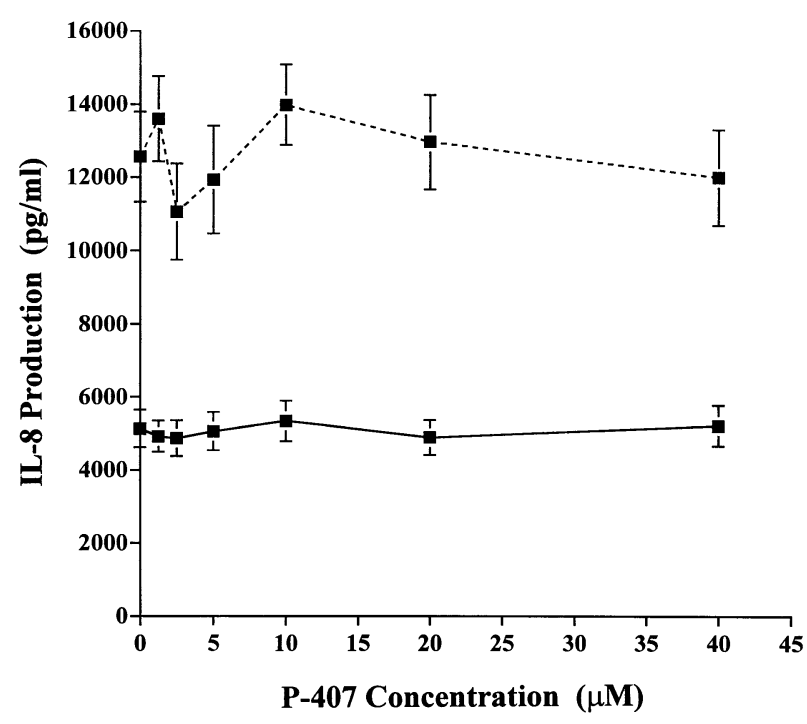

FIG. 2. Effect of P-407 on IL-8 release from HUVEC. Concentration of IL-8 in the absence (solid line, $\mathbf{\square}$ ) and the presence (dashed line, $\mathbf{a})$ of LPS $(50 \mathrm{ng} / \mathrm{ml})$ at $24 \mathrm{~h}$.

addition of $\mathrm{P}-407$ in the concentration range of $1.25-$ $20 \mu \mathrm{M}$ (Fig. 3). As expected, the addition of LPS to the macrophage cell culture resulted in an increase in NO production $(19.9 \pm 0.85 \mu \mathrm{M})$. In the presence of $5-20$ $\mu \mathrm{M}$ P-407, LPS-induced NO production by macrophages was decreased in a dose-dependent fashion.

\section{Extent of lipid oxidation in vitro and in vivo}

As shown in Fig. 4, the mean absorbance value associated with an aqueous solution of P-407 over the concentration range of $0.001-10,000 \mu \mathrm{M}$ was approximately 0.024 . The mean absorbance value for the solution of LDL-C alone was $0.28 \pm 0.037$ and was not significantly different when compared with the mean values of the absorbance for solutions that contained both P-407 and LDL-C (Fig. 4). The latter solutions had a mean absorbance value of approximately 0.3. Only the positive control (i.e. the solution that contained LDL-C, $10 \mathrm{mM} \mathrm{CuSO}_{4}$, and $0.0 \mu \mathrm{M} \mathrm{P}-$ 407) demonstrated an increase in the mean absorbance value to $0.54 \pm 0.063$. This mean absorbance value was not statistically different from the mean absorbance values obtained for the LDL-C and $10 \mathrm{mM}$ 


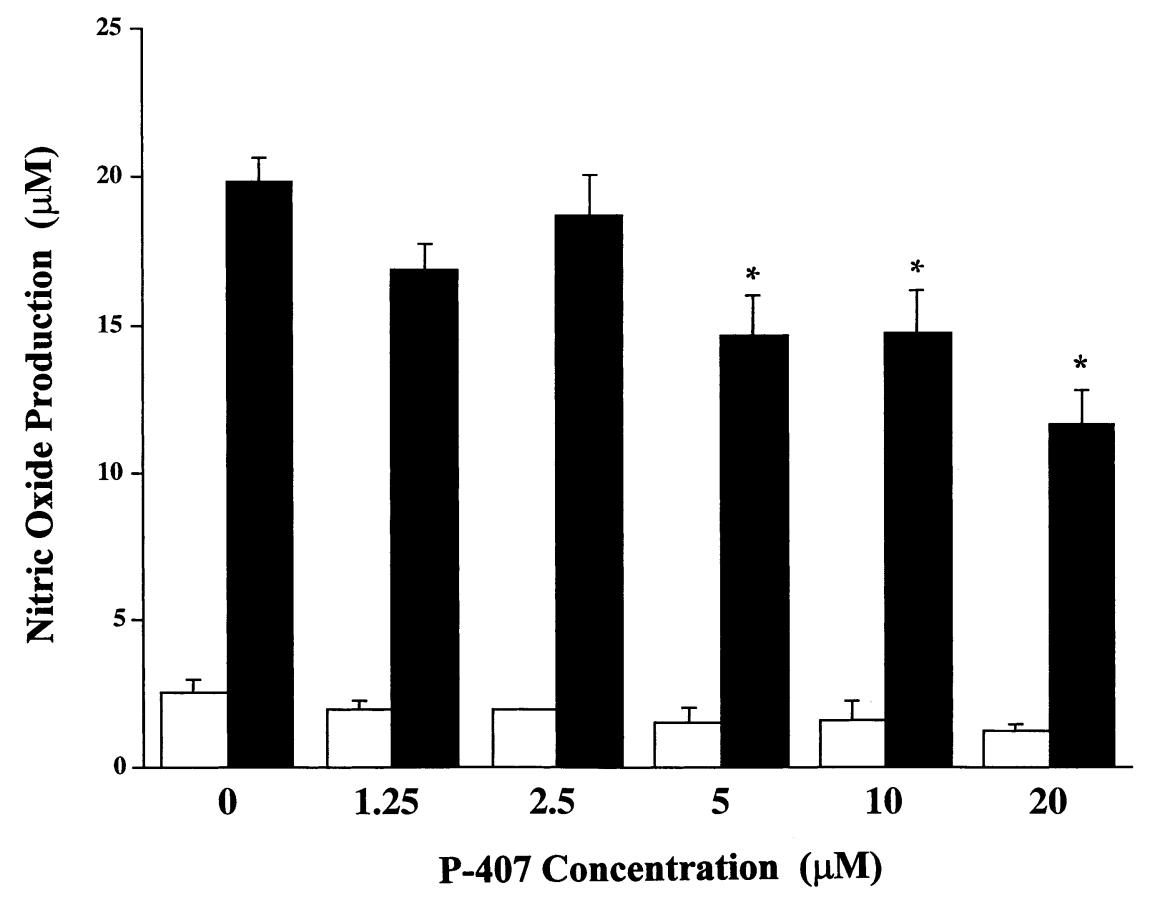

FIG. 3. Effect of P-407 on the release of NO from rat peritoneal macrophages in the absence ( $\square$ ) and presence ( $\square$ ) of LPS (50 $\mathrm{ng} / \mathrm{ml})$ at $24 \mathrm{~h}$. * Significant $(p<0.05)$ decrease in the NO released when individually compared with the NO concentration determined at $0 \mu \mathrm{M}$ P-407.

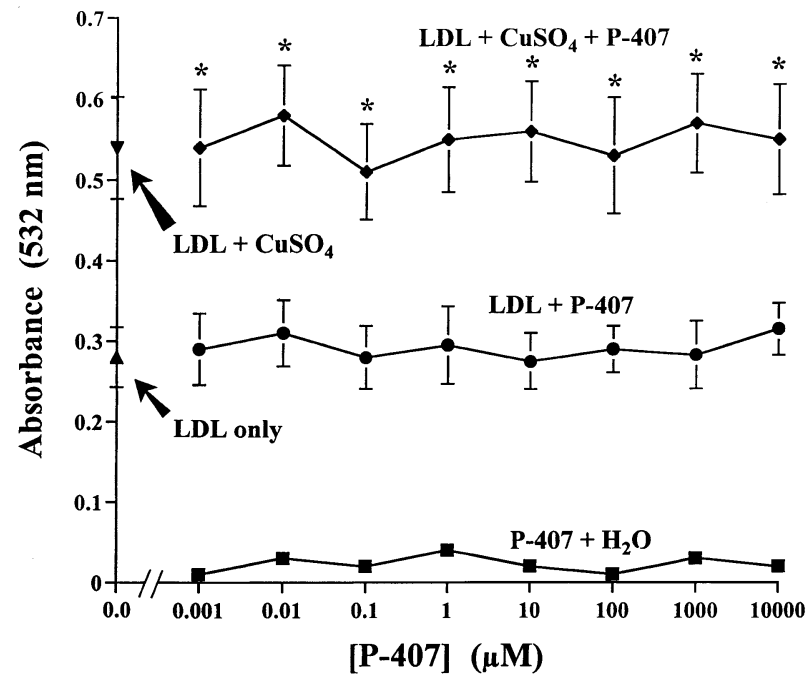

FIG. 4. The effect of P-407 on the oxidation of human lowdensity lipoprotein (LDL) in vitro. ( $\mathbf{\Delta}) \mathrm{LDL}$ alone, ( $\mathbf{\nabla}) \mathrm{LDL}+10$

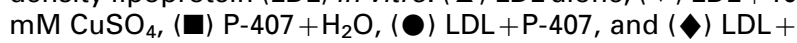
$\mathrm{CuSO}_{4}+\mathrm{P}-407$. All data points represent the mean value \pm standard deviation $(n=4)$. ${ }^{*}$ Significant $(p<0.05)$ increase in the absorbance values relative to mean values for $L D L$ alone and LDL+P-407.

$\mathrm{CuSO}_{4}$ solutions that contained $\mathrm{P}-407$ over the concentration range shown in Fig. 4. The mean absorbance values for the LDL, $10 \mathrm{mM} \mathrm{CuSO}_{4}$, and P-407 solutions shown in Fig. 4 were approximately 0.55 and were significantly $(p<0.05)$ increased compared with corresponding absorbance values for solutions that contained either LDL-C alone $(0.28 \pm 0.037)$ or LDL-C + P-407 ( 0.3).
As can be noted in Fig. 5, the mean absorbance value associated with plasma obtained from mice treated with normal saline for 4 months was $0.52 \pm$ 0.01 , compared with the values of $0.26 \pm 0.12$ and $2.21 \pm 0.33$ for plasma samples obtained from mice that were either fed the high-fat diet or treated with $0.5 \mathrm{~g} / \mathrm{kg} \mathrm{P}-407$ for 4 months, respectively. It should

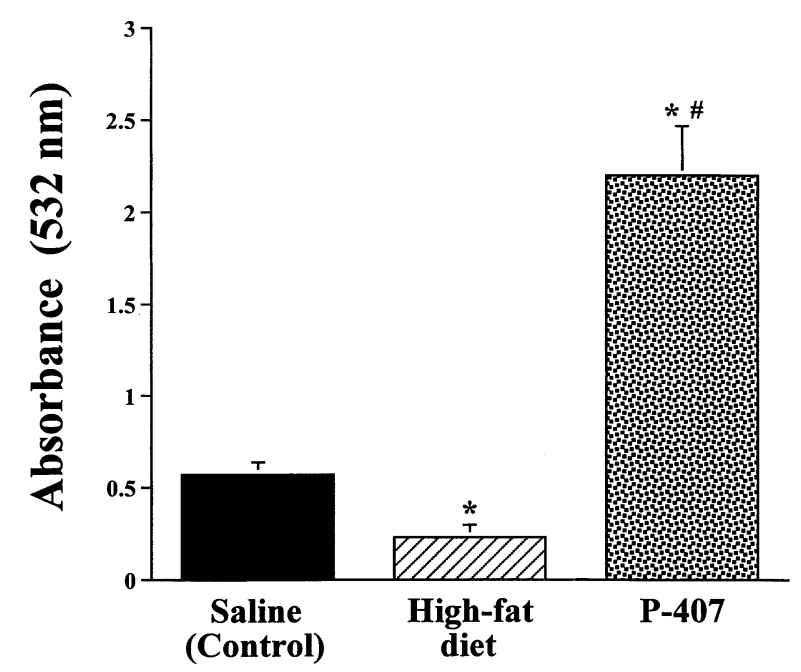

FIG. 5. The effect of a high-fat diet or P-407 treatment on the extent of lipid oxidation in C57BL/6 mice. All bars represent the mean value \pm standard deviation $(n=6)$. * Significant $(P<0.05)$ decrease (high-fat) or increase $(P-407$ treatment) in the mean absorbance value when individually compared with saline-treated controls. \# Significant $(p<0.05)$ increase compared with the mean absorbance value for mice that consumed the high-fat diet. The mean absorbance value for P-407-treated mice was obtained following a nine-fold dilution of the plasma sample. 
be emphasized that the plasma samples obtained from mice treated with P-407 were diluted nine-fold prior to their analysis using the TBARS assay (Fig. 5). Both the extent of oxidation of lipids contained in the plasma of either fat-fed mice or mice treated with P407 (as reflected by the respective mean OD values) were significantly $(p<0.05)$ different when compared with the corresponding mean value for saline-treated mice. In the case of the mice fed the highfat diet, the degree of lipid oxidation was less than the lipid oxidation determined for control mice, whereas with P-407-treated mice the opposite trend was observed (Fig. 5).

\section{Discussion}

The present investigation has attempted to elucidate several variables that may potentially be associated with atheroma formation in the P-407 mouse model of hyperlipidemia and atherosclerosis. In the present study, P-407 was evaluated for its potential to modulate endothelial cell and macrophage functions. $\mathrm{P}-407$ over the concentration range of $0-40 \mu \mathrm{M}$ had no significant effect on the proliferation of human endothelial cells in culture. This was not entirely unexpected since P-407 has previously been used in various biomedical applications. For example, Wang and Johnston ${ }^{29}$ utilized this agent to sustain the release of recombinant IL-2 from an injectable IL-2/ P-407 gel formulation in rats. Prior to their investigation in rats, Johnston et al. ${ }^{30}$ investigated whether IL2 , when formulated with $\mathrm{P}-407$, would still retain its ability to induce proliferation of peripheral blood lymphocytes (PBL) in culture. The proliferation of PBL was unaffected by addition of P-407 below a concentration of $80 \mu \mathrm{M}$ or approximately $0.1 \% \mathrm{w} /$ $\mathrm{w} .{ }^{30}$ In addition, $\mathrm{P}-407$ has been used in cell cultures and in vivo, and has not mediated lysis of myocytes $^{31}{ }^{31}$ erythrocytes ${ }^{29-33}$ and hepatocytes. ${ }^{34}$ The potential of P-407, a non-ionic surface active agent, to decrease the surface tension in a cell culture could potentially affect cell-to-cell contact, and therefore affect proliferation. However, inclusion of P-407 at a concentration less than or equal to $40 \mu \mathrm{M}$ did not affect the proliferation of human endothelial cells in culture.

The present study also demonstrated that P-407, over the concentration range $0-40 \mu \mathrm{M}$, had no capacity to stimulate either IL-6 or IL-8 production by HUVEC, although the cells responded well to LPS. Both IL-6 and IL-8 are inflammatory cytokines produced by endothelial cells, smooth muscle cells, and macrophages. ${ }^{35-40}$ As reported by Rus et al. ${ }^{41}$ the presence of IL- 6 and IL- 8 in the arterial wall where complement activation has also occurred clearly demonstrates the involvement of inflamma- tory events in the initiation and progression of atherosclerosis. Thus, it would appear that P-407 is not proinflammatory to endothelial cells in the vasculature of mice utilized in the P-407-induced mouse model of atherosclerosis. This is fortuitous and perhaps a distinct advantage over fat-fed murine models that must incorporate cholic acid (a potential proinflammagen $^{6}$ ) in the diet to induce aortic lesions. However, it must be noted that oxidized LDL can also induce and modulate the expression of inflammatory cytokines. ${ }^{42}$ However, we found no increase in the concentrations of IL- 6 and IL-8 in the plasma from P407-treated mice (data not shown). Future experiments will determine whether P-407 specifically induces the oxidation of LDL-C in mice.

The production of NO by unactivated macrophages was not affected by P-407 over the concentration range of $0-20 \mu \mathrm{M}$. As expected, incubation of macrophages with LPS markedly elevated NO production. P-407 did not modulate LPS-induced NO production up to a concentration of $2.5 \mu \mathrm{M}$. However, P-407 above a concentration of $2.5 \mu \mathrm{M}$ was inhibitory in a dose-dependent fashion. Nitric oxide is a free radical with an unpaired electron in the highest orbital and has been shown to exhibit both pro-oxidant and anti-oxidant properties. ${ }^{43,44}$ In vitro, $\mathrm{NO}$ is able to inhibit lipid peroxidation. However, NO is rapidly inactivated by the superoxide anion $\left(\mathrm{O}_{2}{ }^{\bullet}\right)$ to form peroxynitrite $\left(\mathrm{ONOO}^{-}\right)$, which is a potent pro-oxidant. This is the mechanism that accounts for the oxidation of LDL-C that occurs when $\mathrm{NO}$ and $\mathrm{O}_{2}$. are simultaneously present in the medium. As NO and $\mathrm{O}_{2}{ }^{\bullet}$ are simultaneously released by activated macrophages, the balance between these two radicals determines the net effect of $\mathrm{NO}$ on lipid peroxidation. ${ }^{44}$ Thus, an excess of NO will favor inhibition of lipid peroxidation while an excess of $\mathrm{O}_{2} \bullet$ or equimolar concentrations of $\mathrm{NO}$ and $\mathrm{O}_{2}{ }^{\bullet}$ will induce lipid peroxidation. ${ }^{44}$ With these relationships in mind, it was interesting to note a significant $(p<$ 0.05 ) decrease in NO production by macrophages cocultured with LPS and P-407 concentrations $\geq 5 \mu \mathrm{M}$ (Fig. 3). A decrease in NO production would tend to favor lipid peroxidation. However, we were not able to conclude unequivocally that P-407 at concentrations $\geq 5 \mu \mathrm{M}$ was directly responsible for the decrease in NO produced by macrophages stimulated with LPS. It may be that P-407 interfered with the activity of LPS to stimulate NO production by macrophages at higher P-407 concentrations $(\geq 5$ $\mu \mathrm{M})$. In contrast, it should be noted that P-407 did not interfere with the activity of LPS to stimulate cytokine (IL-6 and IL-8) production by HUVEC in culture (Figs. 1 and 2), suggesting that inactivation of LPS or competition with LPS may not be the cause. Additional experimentation is required to determine whether the decrease in NO production observed with $\mathrm{P}-407$ at concentrations $\geq 5 \mu \mathrm{M}$ was accompa- 
nied by any change in the concentration of the superoxide anion, $\mathrm{O}_{2}{ }^{\bullet}$. In vivo, an inhibition of $\mathrm{NO}$ production by $\mathrm{P}-407$ may result in vasoconstriction, as $\mathrm{NO}$ is known to cause vasodilation.

Rather than P-407 functioning as a proinflammatory agent with respect to endothelial cells, this compound appears to indirectly result in the oxidation of plasma lipids in P-407-treated mice. Direct action of P-407 to oxidize LDL-C was excluded, since P-407 did not oxidize LDL-C in vitro (Fig. 4). The P407 concentration range shown in Fig. 4 spanned the maximum plasma concentration of $\mathrm{P}-407$ detected in rodents following a single $0.5 \mathrm{~g} / \mathrm{kg}$ injection of $\mathrm{P}$ $407 .{ }^{10}$ In contrast to our in vitro results, plasma from mice treated with P-407 for 4 months revealed a preponderance of oxidized lipids, but not necessarily LDL-C. The TBARS assay lacks specificity for any one lipoprotein associated with cholesterol or triglycerides. Instead, it can only detect the presence of oxidized lipids. However, we have reason to believe that the oxidized lipids may represent oxidized LDL-C since preliminary studies have detected antibodies for malondialdehyde-LDL-C (T.P. Johnston and G.K. Hansson, unpublished findings), and we have previously shown that P-407 treatment in mice induced a shift in the lipoprotein distribution from high-density lipoprotein cholesterol to predominantly LDL-C and from very-low-density lipoprotein cholesterol. ${ }^{14}$ Combined with the data that demonstrated a decrease in the production of NO by macrophages at P407 concentrations $\geq 5 \mu \mathrm{M}$, it may suggest that P-407, by profoundly elevating plasma lipids, indirectly ensures that some of the lipids will undergo oxidation. It is well-known that lipoprotein oxidation plays a key role in atherosclerosis. LDL is oxidized in tissues, including the artery wall, and serves to stimulate the release of oxidation products that activate an inflammatory response. ${ }^{45,46}$ Thus, the P407 mouse model of atherosclerosis may hold promise as a non-transgenic, non-diet-induced animal model of atherosclerosis with which to study the complex mechanisms associated with lipid oxidation and atheroma formation as well as evaluate the efficacy of newer antioxidant drugs.

In conclusion, we have demonstrated that $\mathrm{P}-407$ does not appear to have any inherent proinflammatory activity as suggested by its inability to induce IL- 6 or IL-8 by HUVEC. Additionally, P-407 neither directly oxidized human LDL-C nor modified $\mathrm{CuSO}_{4}-$ mediated lipid oxidation in vitro. However, plasma from P-407-treated mice demonstrated an abundance of oxidized lipids, but not necessarily only oxidized LDL-C. Coupled with the decrease in NO production by cultured macrophages at $\mathrm{P}-407$ concentrations $\geq$ $5 \mu \mathrm{M}, \mathrm{P}-407$ may potentially induce atherosclerosis in male and female $\mathrm{C} 57 \mathrm{BL} / 6$ mice by markedly elevating plasma lipids, disturbing the balance between $\mathrm{NO}$ and $\mathrm{O}_{2}{ }^{\circ}$, and indirectly causing excess lipids to undergo oxidation. These findings would seem more closely aligned with the 'modified' (oxidized) LDL-C theory for the pathogenesis of atherosclerosis, and may offer a valuable new mouse model for the study of human coronary heart disease and the benefits associated with effective antioxidant drug therapy.

ACKNOWLEDGEMENTS. This work was supported, in part, from a Grant-InAid from the American Heart Association-Kansas Affiliate (to T.P.J. and to K.N.D.) and in part by the Joseph and Elizabeth Carey Arthritis Funds from the Kansas University Endowment Association (to D.J.S.).

\section{References}

1. Anderson KM, Castelli WP, Levy D. Cholesterol and mortality: 30 years of follow-up from the Framingham Study. J Am Med Assoc 1987; 257: 2176-2180.

2. The Expert Panel. Report of the National Cholesterol Education Program Expert Panel in detection, evaluation, and treatment of high blood pressure in adults. Arch Intern Med 1988; 148: 36-69.

3. Jokinen M, Clarkson T, Prichard R. Animal models in atherosclerosis research. Exp Mol Patol 1985; 42: 1-28.

4. Van Lenten B. Animal models: the Watanabe heritable hyperlipidemic rabbit. In: Lusis A, Sparkes S, eds. Genetic Factors in Atherosclerosis: Approaches and Model Systems, Basel: Karger, 1989: 125-138.

5. Rapacz J, Hasler-Rapacz J. Animal models: the pig. In: Lusis A, Sparkes S, eds. Genetic Factors in Atherosclerosis: Approaches and Model Systems, Basel: Karger, 1989: 139-169.

6. Breslow JL. Mouse models of atherogenesis. Science 1996; 272: 685688.

7. Paigen B, Plump AS, Rubin EM. The mouse as a model for human cardiovascular disease and hyperlipidemia. Curr Opin Lipidol 1994; 5: $258-264$.

8. Wout Z, Pec EA, Johnston TP. Poloxamer 407-mediated changes in plasma cholesterol and triglycerides following intraperitoneal injections to rats. J Parent Sci Technol 1992; 46: 192-200.

9. Johnston TP, Palmer WK. Mechanism of poloxamer 407-induced hypertriglyceridemia in the rat. Biochem Pharmacol 1993; 46: 10371042.

10. Li C, Palmer WK, Johnston TP. Disposition of poloxamer 407 following intraperitoneal injection to rats. J Pharm Biomed Anal 1996; 14: 659665 .

11. Johnston TP, Palmer WK. Effect of poloxamer 407 on the activity of microsomal 3-hydroxy-3-methylglutaryl CoA reductase in rats. $J$ Cardiovasc Pharmacol 1997; 29: 580-585.

12. Palmer WK, Emeson EE, Johnston TP. The poloxamer 407-induced hyperlipidemic atherogenic animal model. Med Sci Sports Exer 1997; 29: $1416-1421$

13. Palmer WK, Emeson EE, Johnston TP. Poloxamer 407-induced atherogenesis in the C57BL/6 mouse. Atherosclerosis 1998; 136: 115-123.

14. Johnston TP, Baker JC, Hall D, Jamal AS, Emeson EE, Palmer WK Potential downregulation of HMG-CoA reductase following chronic administration of P-407 to C57BL/6 mice. J Cardiovasc Pharmacol 1999; 34: $831-842$.

15. Johnston TP, Baker JC, Hall D, Jamal AS, Emeson EE, Palmer WK. Regression of poloxamer 407-induced atherosclerotic lesions in C57BL/6 mice using atorvastatin. Atherosclerosis 2000; 149: 303-313.

16. Johnston TP, Coker JW, Paigen BJ, Tawfik OW. Sex does not seem to influence the formation of aortic lesions in the P-407-induced mouse model of hyperlipidemia and atherosclerosis. J Cardiovasc Pharmacol 2002; 39: 404-411

17. Wasan KM, Subramanian R, Kwong M, Goldberg IJ, Wright T, Johnston TP. Poloxamer 407-mediated alterations in the activities of enzymes regulating cholesterol and triglyceride transport and metabolism in rats. $J$ Pharm Pharmaceut Sci 2003; in press.

18. Johnston TP, Nguyen LB, Chu WA, Shefer S. Potency of select statin drugs in a new mouse model of hyperlipidemia and atherosclerosis. Int $J$ Pharm 2001; 229: 75-86.

19. Porter J, Carter B, Johnston TP, Palmer WK. Effect of pravastatin on poloxamer 407-induced hyperlipidemia in rats. Pharmacotherapy 1995; 15: $92-98$.

20. Nash VJ, Johnston TP, Palmer WK. Effects of nicotinic acid on poloxamer 407-induced hyperlipidemia. Pharmacotherapy 1996; 16: 10-15.

21. Nash VJ. Effects of hypolipidemic drugs on poloxamer 407-induced hyperlipidemia. M.S. Thesis. Chicago, IL: University of Illinois at Chicago, 1994: 1-164.

22. Li Y, Stechschulte AC, Smith DD, Lindsley HB, Stechschulte DJ, Dileepan $\mathrm{KN}$. Mast cell granules potentiate endotoxin-induced interleukin-6 production by endothelial cells. J Leuk Biol 1997; 62: 210-216. 
23. Li Y, Nguyen D, Stechschulte AC, Stechschulte DJ, Dileepan KN. Effect of mast cell granules on the gene expression of nitric oxide synthase and tumor necrosis factor- $\alpha$ in macrophages. Mediat Inflamm 1998; 7: $355-$ 361.

24. Li Y, Chi L, Stechschulte DJ, Dileepan KN. Histamine-induced production of interleukin- 6 and interleukin- 8 by human coronary artery endothelial cells. Microvascular Res 2001; 61: 253-262.

25. Jehle AB, Li Y, Stechschulte AC, Stechschulte DJ, Dileepan KN. Endotoxin and mast cell granule proteases synergistically activate human coronary artery endothelial cells to generate interleukin- 6 and interleukin-8. J Interferon Cytokine Res 2000; 20: 361-368.

26. Dileepan KN, Lorsbach RB, Stechschulte DJ. Mast cell granules inhibit macrophage-mediated lysis of mastocytoma cells (P815) and nitric oxide production. I Leuk Biol 1993; 53: 446-453.

27. Schmedes A, Hølmer G. A new thiobarbituric acid (TBA) method for determining free malondialdehyde (MDA) and hydroperoxides selectively as a measure of lipid peroxidation. J Am Oil Chem Soc 1989; 66 $813-817$.

28. Snedecor GW, Cochran WG. Tests of hypotheses. In: Snedecor GW, Cochran GW, eds. Statistical Methods, Ames, IA: Iowa State University Press, 1980: 64-82.

29. Wang P, Johnston TP. Sustained release interleukin-2 following intramuscular injection in rats. Int J Pharm 1995; 113: 73-81.

30. Johnston TP, Punjabi MA, Froelich CJ. Sustained delivery of interleukin-2 from a poloxamer 407 gel matrix following intraperitoneal injection in mice. Pharm Res 1992; 9: 421-430.

31. Johnston TP, Miller SC. Toxicological evaluation of poloxamers for intramuscular use. J Parenter Sci Technol 1985; 39: 83-88.

32. Atkinson TP, Bullock JO, Smith TF, Mullins RE, Hunter RL. Ion transport mediated by copolymers composed of polyoxyethylene and polyoxypropylene. Am J Physiol 1988; 254: C20-C26.

33. Pec EA, Wout ZG, Johnston TP. Biological activity of urease formulated in poloxamer 407 following intraperitoneal injection in the rat. J Pharm Sci 1992; 81: 626-630.

34. Muller RH. Toxicity studies in hepatocyte cultures. In: Muller RH, ed. Colloidal Carriers for Controlled Drug Delivery and Targeting, Boca Raton, FL: CRC Press, 1991: 207-210.
35. Akira S, Taga T, Kishimoto T. Interleukin- 6 in biology and medicine. $A d v$ Immunol 1993; 54: 1-78.

36. Aarden L, Helle M, Boeije L, Pascual-Salcedo D, de Groot E. Differential induction of interleukin-6 production in monocytes, endothelial cells, and smooth muscle cells. Eur Cytokine Net 1991; 2: 115-120.

37. Gimbrone Jr M, Obin MS, Brock AF, et al. Endothelial interleukin-8: a novel inhibitor of leukocyte-endothelial interactions. Science 1989; 246: $1601-1603$.

38. Baggiolini M, Dewald B, Moser B I. nterleukin-8 and related chemotactic cytokines-CXC and CC chemokines. Adv Immunol 1993; 55: 97-179.

39. Wang JM, Sica A, Peri G, et al. Expression of moncyte chemotactic protein and interleukin- 8 by cytokine-activated human vascular smooth muscle cells. Arterioscler Thromb 1991; 11: 1166-1174.

40. Brown Z, Gerritsen ME, Carley WW, Strieter RM, Kunkel SL, Westwick J. Chemokine gene expression and secretion by cytokine-activated human microvascular endothelial cells. Am J Pathol 1994; 145: 913-921.

41. Rus HG, Vlaicu R, Niculescu F. Interleukin-6 and interleukin-8 protein and gene expression in human arterial atherosclerotic wall. Atherosclerosis 1996; 127: 263-271.

42. Terkeltaub R, Banka CL, Solan J, Santoro D, Brand K, Curtiss LK. Oxidized LDL induces monocytic cell expression of interleukin- 8 , a chemokine with T-lymphocyte chemotactic activity. Arterioscler Thromb 1994; 14: 47-53.

43. Patel RP, Levonen AL, Crawford JH, Darley-Usmar VM. Mechanisms of the pro- and anti-oxidant actions of nitric oxide in atherosclerosis. Atherosclerosis 2000; 47: 465-474.

44. Violi F, Marino R, Milite MT, Loffredo L. Nitric oxide and its role in lipid peroxidation. Diabetes Metab Res Rev 1999; 15: 283-288.

45. Steinberg D, Parthasarathy S, Carew TE, Khoo JC, Witztum JL. Beyond cholesterol: modifications of low-density-lipoprotein that increase its atherogenicity. N Engl J Med 1989; 320: 915-924.

46. Witztum JL, Steinberg D. Role of oxidized low-density-lipoprotein in atherogenesis. J Clin Invest 1992; 90: 1138-1144.

\section{Received 14 March 2003}

Accepted 7 April 2003 


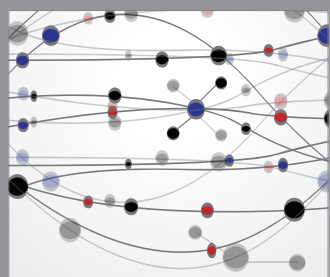

The Scientific World Journal
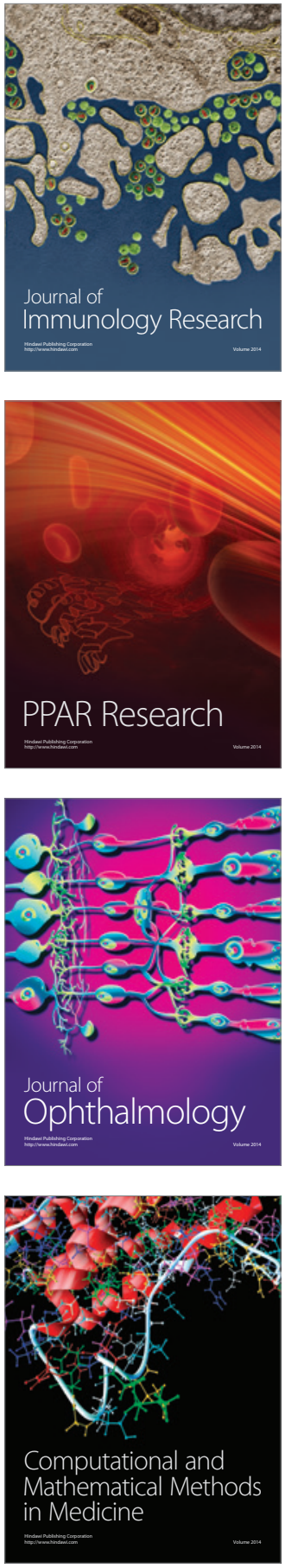

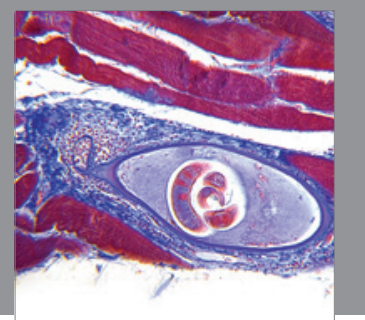

Gastroenterology

Research and Practice
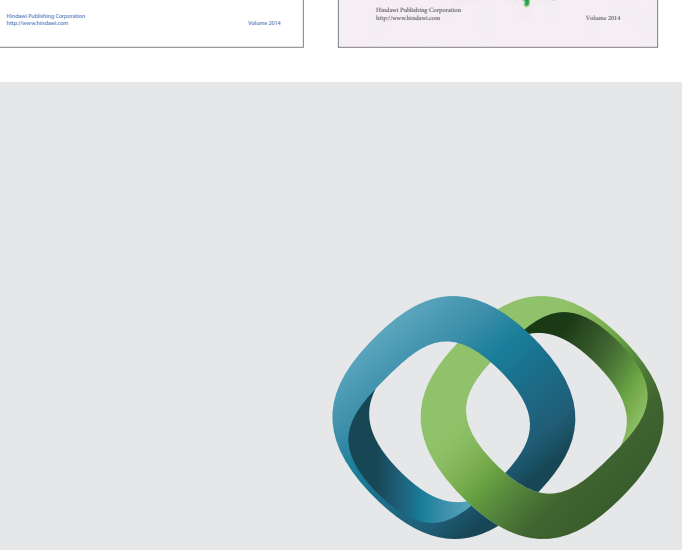

\section{Hindawi}

Submit your manuscripts at

http://www.hindawi.com
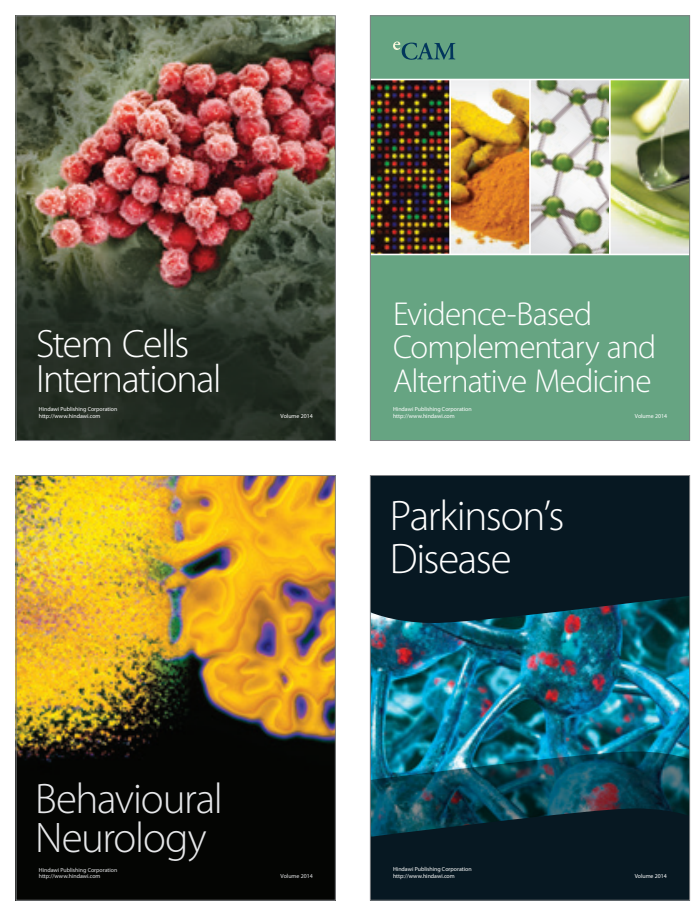

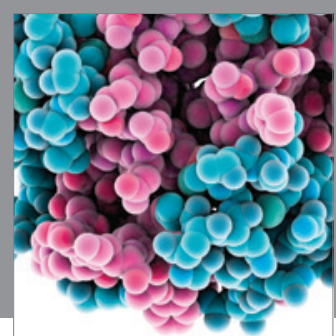

Journal of
Diabetes Research

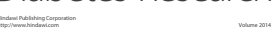

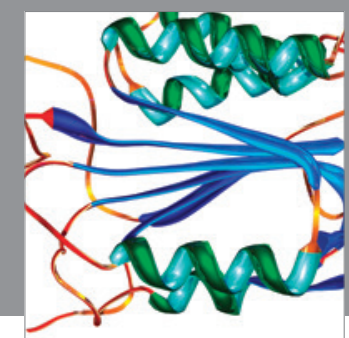

Disease Markers
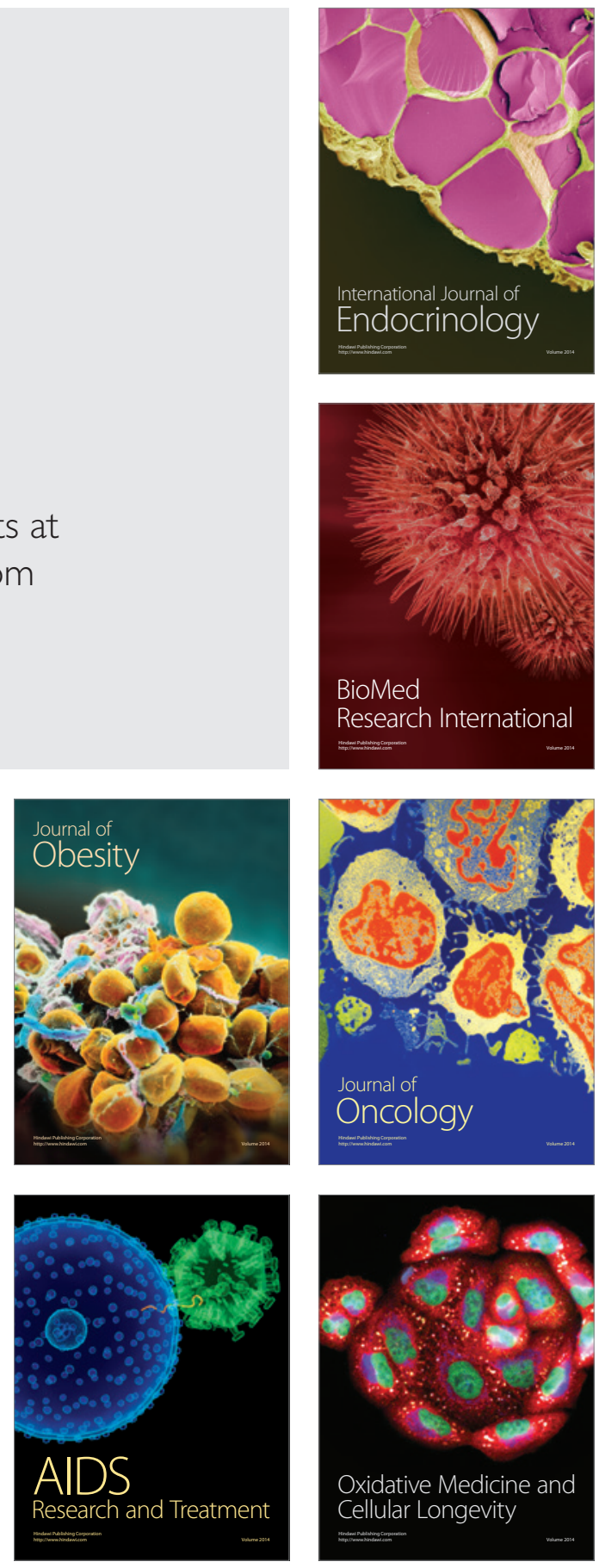